\title{
Correction to: Genetic analysis of multi-environmental spring wheat trials identifies genomic regions for locus-specific trade-offs for grain weight and grain number
}

\author{
Sivakumar Sukumaran $^{1}$ (D) $\cdot$ Marta Lopes $^{2} \cdot$ Susanne Dreisigacker $^{1} \cdot$ Matthew Reynolds $^{1}$
}

Published online: 16 February 2018

○) Springer-Verlag GmbH Germany, part of Springer Nature 2018

\section{Correction to: Theoretical and Applied Genetics} https://doi.org/10.1007/s00122-017-3037-7

Unfortunately, the Fig. 1 of this original article was incorrectly published. The corrected Fig. 1 is given below.
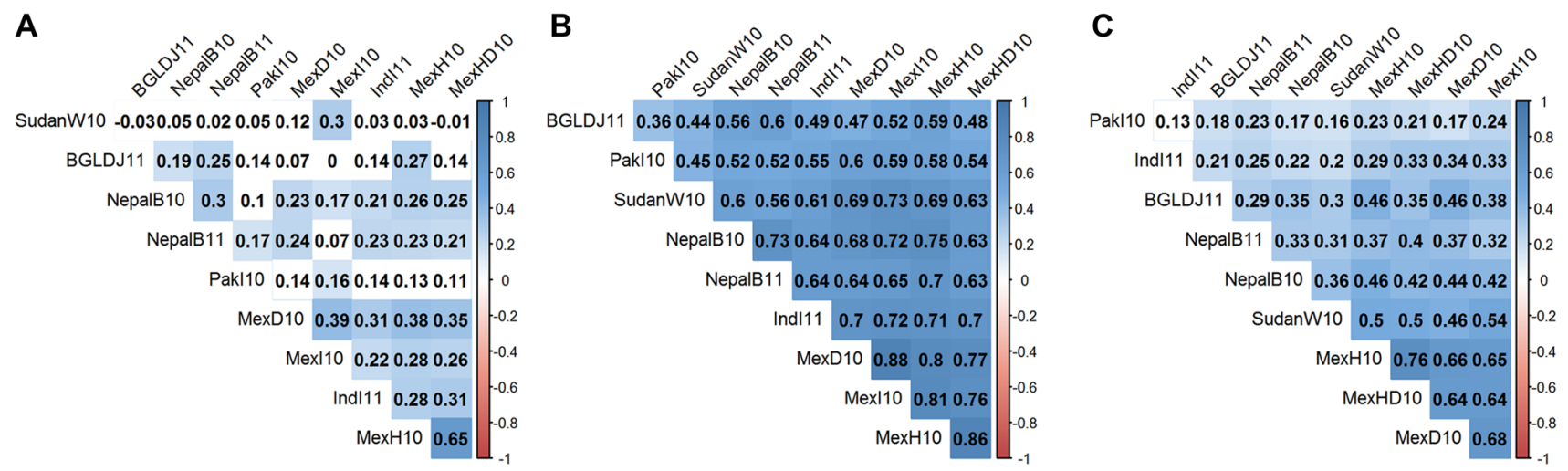

Fig. 1 Phenotypic correlations of the traits a grain yield, $\mathbf{b}$ thousand grain weight, and $\mathbf{c}$ grain number between the locations. Blue shades indicate significance at $\alpha<0.001$. Refer to table one for abbreviations (color figure online)

The original article can be found online at https://doi.org/10.1007/ s00122-017-3037-7.

Sivakumar Sukumaran

s.sukumaran@cgiar.org

1 Global Wheat Program, International Maize and Wheat Improvement Center (CIMMYT), Apdo. Postal 6-641, Mexico City 06600, Mexico

2 CIMMYT, P.O. Box 39, Emek, Ankara 06511, Turkey 